\title{
Women, healthcare leadership and societal culture: a qualitative study
}

\begin{abstract}
Stavroula Kalaitzi,'
Katarzyna Czabanowska, ${ }^{1,2}$

Natasha Azzopardi-Muscat, ${ }^{3}$

Liliana Cuschieri, ${ }^{4}$ Elena

Petelos, ${ }^{5,6}$ Maria Papadakaki, ${ }^{7}$

Suzanne Babich ${ }^{1,8}$

'Department of International Health, Care and Public Health Research Institute (CAPHRI), Faculty of Health, Medicine and Life Sciences, Maastricht University, Maastricht, the Netherlands; ${ }^{2}$ Department of Health Policy and Management, Institute of Public Health, Faculty of Health Sciences, Jagellonian University, Krakow, Poland; ${ }^{3}$ Department of Health Services Management, Faculty of Health Sciences, University of Malta, Msida, Malta; ${ }^{4}$ Department for Policy in Health, Ministry for Health, Valletta, Malta; ${ }^{5} \mathrm{Clinic}$ of Social and Family Medicine, Department of Social Medicine, School of Medicine, University of Crete, Iraklion, Greece; ${ }^{6}$ Department of Health Services Research, Care and Public Health Research Institute (CAPHRI) Faculty of Health, Medicine and Life Sciences, Maastricht University, Maastricht, the Netherlands; ${ }^{7}$ Department of Social Work, School of Health and Social Welfare, Technological Educational Institute of Crete, Iraklion, Greece; ${ }^{8}$ Department of Health Policy and Management, Richard M. Fairbanks School of Public Health, Indianapolis, IN, USA
\end{abstract}

Correspondence: Stavroula Kalaitzi Department of International Health, Care and Public Health Research Institute (CAPHRI), Faculty of Health, Medicine and Life Sciences, Maastricht University, Duboisdomein 30, 6229 GT Maastricht, the Netherlands

Tel +30 6932285055

Email valia.kalaitzi@maastrichtuniversity.nl
Purpose: Women leaders encounter societal and cultural challenges that define and diminish their career potential. This occurs across several professions including healthcare. Scant attention has been drawn to the discursive dynamics among gender, healthcare leadership and societal culture. The aim of this study is to assess empirically gendered barriers to women's leadership in healthcare through the lens of sociocultural characteristics. The comparative study was conducted in Greece and Malta. The interest in these countries stems from their poor performance in the gender employment gap and the rapid sociocultural and economic changes occurring in the European-Mediterranean region.

Subjects and methods: Thirty-six individual in-depth interviews were conducted with healthcare leaders, including both women and men (18 women and 18 men). Directed content analysis was used to identify and analyze themes against the coding scheme of the Barriers Thematic Map to women's leadership. Summative content analysis was applied to quantify the usage of themes, while qualitative meta-summative method was used to interpret and contextualize the findings. Results: Twenty and twenty-one barriers to women's leadership were identified within the Greek and Maltese healthcare settings, respectively. Prevailing barriers included work/life balance, lack of family (spousal) support, culture, stereotypes, gender bias and lack of social support. Inter-country similarities and differences in prevalence of the identified barriers were observed. Conclusion: The study appraised empirically the gendered barriers that women encounter in healthcare leadership through the lens of national sociocultural specificities. Findings unveiled underlying interactions among gender, leadership and countries' sociocultural contexts, which may elucidate the varying degrees of strength of norms and barriers embedded in a society's egalitarian practices. Cultural tightness has been found to be experienced by societal dividends as an alibi or barrier against sociocultural transformation. Findings informed a conceptual framework proposed to advance research in the area of women's leadership.

Keywords: gendered barriers, sociocultural contexts, Greece, Malta, directed content analysis

\section{Introduction}

Cultures are never static. They are in a constant process of flux and negotiations, adapting and changing over time and space. Helman ${ }^{1}$ stated that culture must always be seen in its particular context made up of, among others, socioeconomic factors. Leach $^{2}$ held that the cultural lens which societal divisions, such as profession and gender, develop are imbued with different values, rules and perspectives on life. These often coexist uncomfortably within the same social context. Intersecting identities, namely, "the mutually constitutive relations among social identities" (Shields, 2008, p. 301), ${ }^{3}$ reflect the individual's social location, beliefs, perceptions and power 
relations embedded within. ${ }^{4}$ Along that perspective, Maurice ${ }^{5}$ underlined the importance of interplay between societal and professional settings within countries' cultural boundaries. These were articulated by Foucault ${ }^{6}$ as "regimes of truth", namely, discourses in time and context bearing an "invisible power" under their cultural capacity. ${ }^{7}$ Likewise, the leadership prism exhibits itself differently in each context and culture. This is also true in relation to women leaders and culturally legitimized social power and authority. ${ }^{7-9}$ Literature has dealt with asymmetries in cultural evaluations of gender within geographic boundaries. Unveiling women's voice is one the most important missing voices in the majority of western accounts of culture..$^{9,11}$

\section{Delimiting countries' sociocultural contexts}

This study focuses on two countries in the European Union (EU)-Mediterranean (Med) region. Greece has been heavily affected by the global financial crisis and the ensuing burden generated various economic, political, social and cultural impacts. Malta, while not having been seriously negatively affected by the financial crisis, has experienced a rapid sociocultural transition in recent years. ${ }^{12,13}$ These economic and social changes are both relevant to gender and power dimensions. ${ }^{14}$ The authors focused on Greece and Malta, two EU-Med countries, which have been ranked low-to-middle in the Gender Equality Index ${ }^{15}$ and are among the worst performers in terms of gender employment gap. ${ }^{16-18}$ The objective lies in understanding similarities and differences in sociocultural and economic contexts with reference to the explored phenomenon by highlighting the "structures and systems that support or inhibit women on the path toward leadership in health". ${ }^{19}$

\section{Greece}

Greece has been profoundly affected by the devastating economic crisis which generated harsh social and economic implications; it is considered as an "omens of a Greek tragedy", referring among others to the deepening lack of proper healthcare delivery. ${ }^{18}$ The healthcare system suffered dramatically ${ }^{20}$ and had been previously reported as "a major factor" contributing to the country's economic hardship. As such, it came under intense scrutiny. ${ }^{21}$ Dramatic reductions in health sector salaries and changes to working conditions, such as employment under fixed-term contracts, resulted in hasty retirements to ensure better pensions, even substantially reduced, and in understaffing and poor quality of healthcare delivery. ${ }^{21}$ Health indicators deteriorated, including child and elderly health, due to decline in public spending and household income. ${ }^{22,23}$ The crisis affected predominantly women and single-parent families, especially in the health, education and social care sectors; ${ }^{24,25}$ women who were tertiary education graduates were concentrated in less-rewarding, but economically safer disciplines. ${ }^{26}$ The ensuing social and economic constraints forced women to make the culturally expected and accepted choice to prioritize family support and care, formal or informal, over pursuit of career advancement according to the power structure of Greek society. ${ }^{27}$ Being a collectivist culture, Greek society values the family unit, which remains male dominated. The social pattern touches upon patriarchy, expecting women to assume less authority and power than spouses within social and family boundaries and to continue to be responsible for household duties despite a high level of education and contribution to the household income. ${ }^{28}$ In a nutshell, cultural, economic and political processes embedded in an institutional and societal context had an important effect on labor choices and women's senses of worth within the Greek society. ${ }^{29}$ The devastating financial crisis in Greece since 2009 has jeopardized any progress gained in gender equality and equal work opportunities, triggering a backlash in employment practices and choices. ${ }^{24}$

\section{Malta}

Malta has been traditionally a patriarchal, deeply religious society, which was further influenced by the impact of British colonialism and the country's relative geographic isolation. ${ }^{30}$ Historically, Maltese women became professionally active in caring positions in the domestic, education or health sectors. ${ }^{31}$ Emancipation was given a push forward because of conscription during the Second World War which, over a period of time, eventually resulted in their taking on various roles including the directorship of hospitals and full professorship in academy. ${ }^{31,32}$ However, the long-standing, socially constructed, gendered norms and expectations dictated prioritization of household and child-rearing tasks over a career. Thus, women were prevented from achieving their full potential in terms of empowerment and leadership. ${ }^{33}$ In 2004, women represented only $32.6 \%$ of the Maltese labor market, with many opting for part-time work to reconcile work with family demands, resulting in ongoing situations of economic hardship and dependence. ${ }^{16}$ Additionally, sectorial and occupational segregation still abounds with many opting for family-friendly employment, such as education, service workers and assistant professionals. ${ }^{16}$ Although the policy agenda has changed and structural measures, including availability of free child care, have been adopted, enabling 
great strides forward to be accomplished over a few years, sociocultural resistance remains strong. Discrimination and rigid stereotypes in relation to family roles keep limiting women's participation in the labor market, and in corporate and political roles, despite high educational levels and professional experience. ${ }^{34}$ Advances among younger couples have not yet superseded the social norm which expects women to shape their life choices to fit in their husbands' interests since "God forbid if a husband would have to adapt his life to suit his wife's lifestyle" (p. 23). ${ }^{24}$ In essence, the country is still performing poorly in women's leadership and gender equality; the Global Gender Gap Report 2016 states that Malta is one of the three lowest performing countries in Western Europe regarding gender equality. ${ }^{17}$

\section{Health care sector and women's leadership}

Studying the healthcare sector ${ }^{5}$ may identify and explain the distinctiveness of barriers specifically experienced by women leaders in this setting by exploring the interplay between sector and societal settings within countries' cultural boundaries. The value of analyzing the relationship between the country-specific sectoral framework and dominant sociocultural and economic factors shaping social reality derives from the position that actors cannot be separated from structures and vice versa. Actors intrinsically participate in a way or another in building the social reality in which they are active. ${ }^{35}$ Comparison and extrapolation of the phenomenon through the lens of social and cultural diversity between countries may establish a basis to better understand the relationship of dominant sociocultural factors and barriers hindering women's leadership advancement.

Previous research confirms that women fall severely behind men in assuming leading roles in healthcare as they are hindered by numerous barriers. ${ }^{36-39}$ Even though their added value in the healthcare sector is acknowledged, ${ }^{40,41}$ women leaders encounter societal and cultural challenges that define and diminish their career potential. This study considers the dynamic dialogue among societal culture, professional leadership and gender as a socially constructed concept ${ }^{40}$ pervading the society in a constant flux and negotiation. These interactions shape mechanisms over time, such that dominant perceptions are enabled and constantly reinforced through country's social, cultural and economic influences.

This paper draws upon qualitative data which are used to understand the social phenomenon of women leaders' underrepresentation in healthcare sector by unveiling the underlying dynamics among women, healthcare leadership and country's specific societal culture. ${ }^{35}$ Taking into account that the healthcare sector constitutes one of the biggest employers worldwide and is populated mainly by women, ${ }^{36}$ researchers sought to explore the dominant factors, such as culturally imbued norms, affecting women in this setting; roles and values assumed by healthcare leaders reflecting external influences such as education, family, community and peers are also considered. ${ }^{43}$ The aim of this study is to assess empirically the gendered barriers encountered by women leaders in healthcare through country's sociocultural specificity.

\section{Subjects and Methods}

The researchers undertook a small exploratory, qualitative study using semi-structured interviews ${ }^{44}$ to "put people in the context of their lives and the lives of those around them". ${ }^{45}$ The research question addressed was "What are the barriers and their importance in shaping women's leadership in Greek and Maltese healthcare settings?" Authors set out to critically evaluate and contextualize the empirical findings to gain in-depth understanding of the relationship between the barriers identified as hindering the advancement of women leaders in healthcare within the country-specific sociocultural and economic contexts. ${ }^{46}$

\section{Ethical approval}

Ethical approval was obtained from the ethics committees of the Maastricht University (No. METC 16-4-266; January 19, 2017), the National and Kapodistrian University of Athens (Medical School) (February 3, 2017) and the University of Malta (March 10, 2017).

\section{Study design}

The study used a non-experimental, descriptive design. Thirty-six semi-structured interviews were conducted with the healthcare leaders in Greece and Malta. Gender balance was achieved in the purposive sampling of interviewees from the academic, clinical and medical groups to ensure the best possible inclusive insights with regards to the research question posed (Figure 1).

\section{Participant recruitment}

Geographically defined urban areas were conveniently selected in Greece for the needs of sample selection: Athens, Thessaloniki, Patra and Heraklion for Greece. National sampling was performed in Malta. A number of eligible organizations/ agencies operating in the district were identified, representing the academic, clinical and medical facets (eg, medical schools, hospitals, medical associations) in the healthcare sector. Academic leaders included trained medical practitioners at the level of full professor. Clinical leaders included trained medical practitioners holding the position of chief executive 


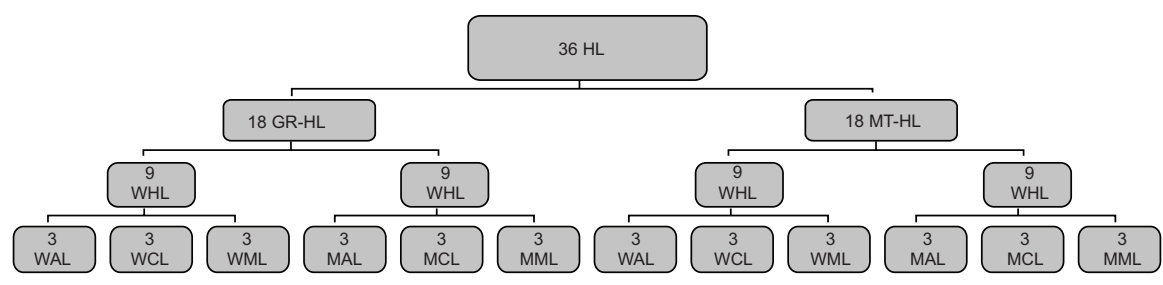

Figure I Study design - interviewees.

Abbreviations: GR, Greece; HL, healthcare leaders; MAL, men academic leaders; MCL, men clinical leaders; MML, men medical leaders; MT, Malta; WAL, women academic leaders; WCL, women clinical leaders; WML, women medical leaders.

officer or board member or a clinical directorship in a public or private hospital. Medical leaders included trained medical practitioners presiding over a professional organization and/ or holding top leading positions in health ministry, health or medical organizations. ${ }^{45}$ Purposeful and snowball sampling were used to identify participants in the research team members' networks in each country, rippling outward to wider networks of linked colleagues and agencies. Three men and three women were selected per facet and per country, namely, 18 participants per country and 36 participants in total (Figure 1). The purposeful sampling of 18 participants per country provided variation in the facets and participants in this study. The number was sufficient to reach thematic saturation. ${ }^{45,47}$

\section{Research procedures}

Potential interviewees were approached by phone or email; all participants agreed to participate and were interviewed with no subsequent dropouts. Greek leaders were interviewed between March 2017 and October 2017; Maltese leaders were interviewed between June 2017 and August 2017. Interviewees were free to choose between a face-to-face interview, with their office as the interview setting, and a telephone interview. In both cases, both interviewee and researcher confirmed that nobody else was present during interviewing. Interviews were recorded with the interviewee's consent, except for two Greek interviewees who asked researcher SK to take field notes by hand. Interviewees were asked if they wished to confirm transcription output, but they declined due to time constraints. Transcription output was reviewed by two members of the research team (MP and SB). Interviews were conducted in Greek for Greek native interviewees and translated into English by a third party, and in English for Maltese interviewees since English is an official language in Malta. Researchers SK, EP and MP checked the translated Greek texts separately to increase the reliability of the data. ${ }^{48}$

Prior to the interview, participants were informed orally and in writing about the study objectives, methods and data protection, and granted their consent including signing an informed consent form. Two experienced members of the research team (SK and LC) carried out the semi-structured interviews; inter- views lasted from 20 to 50 minutes. The interview questionnaire focused on the nature of encountered barriers, on reasoning and potential ways to overcome them (Figure 2) and was informed by the output of a previously conducted systematic literature review pertaining to gendered barriers to women's leadership in healthcare ${ }^{49}$ and by dedicated workshops and focus groups. ${ }^{50,51}$

\section{Analyses}

Following each interview, interviewers noted initial thoughts and ideas. Field notes and transcribed interviews were read several times by four researchers to gain close immersion in the data. More specifically, a case description was initially drafted for each of the 36 interviews using all data. Then, the process included data coding into meaningful groups using the coding scheme of the Barriers Thematic Map (BTM). ${ }^{49}$

Researchers adopted the BTM coding scheme to contrast the study's findings on the grounds of comprehensiveness and provided prevalence (Figure 3). BTM illustrates a comprehensive list of 26 barriers to women's leadership with varying degrees of prevalence resulting from a systematic literature review with European coverage ranging from 2000 to 2015; the list has also been validated by several experts and focus groups during dedicated workshops. ${ }^{50,51}$ Thereby, the BTM was deemed to offer an educated, context-free (both at country and sector levels), theoretical basis on barriers to women's leadership in healthcare. The prevalence component was considered useful in terms of a comprehensive approach of barriers; it served the objectives of this empirical study by means of providing a comparative tool to explore similarities and differences between researched countries and extrapolate evidence-based conclusions.

Two randomly selected interviews per participant country were piloted for decoding and matching with BTM for the purposes of performing a validity check. The list of different BTM codes was then sorted into potential themes by gendered barriers encountered by healthcare leaders, based on patterns of meaning. ${ }^{52}$ Two experienced qualitative researchers per participant country coded interviews' data independently from the raw data and applied pattern matching technique with BTM (Greece: EP, MP; Malta: NA, LC). 
Interview questionnaire for the study:

"Exploring barriers to women's leadership in Greek and Maltese healthcare setting"

1. How did you become a professor in medical school/hospital CEO/president of the health body?

2. What is your education level?

3. Please tell us about your experiences in professorship/top level administration/presidency in terms of gender diversity (eg, easier/tougher as a woman/man, relationship with male/female colleagues, administrators, students, etc)

4. What barriers/difficulties related to your gender if any have you faced during your carrier advancement?

5. Would you please elaborate further on the nature of the barriers you faced? (probe question)

6. What according to you might have been the reasons of the barriers you faced?

7. How did you feel when confronted with the barriers? How did you deal with them? Have you been offered opportunities during your carrier advancement related to your gender? Why? Why not?

8. Have you had any support while advancing in your career? If so from whom?

9. What are your thoughts about gender diversity in your field?

10. What does gender equality mean to you?

11. What is your advice to younger female professionals who want to make career in the healthcare field?

12. What is your advice to younger male professionals who want to make career in the healthcare field?

Figure 2 The interview questionnaire.
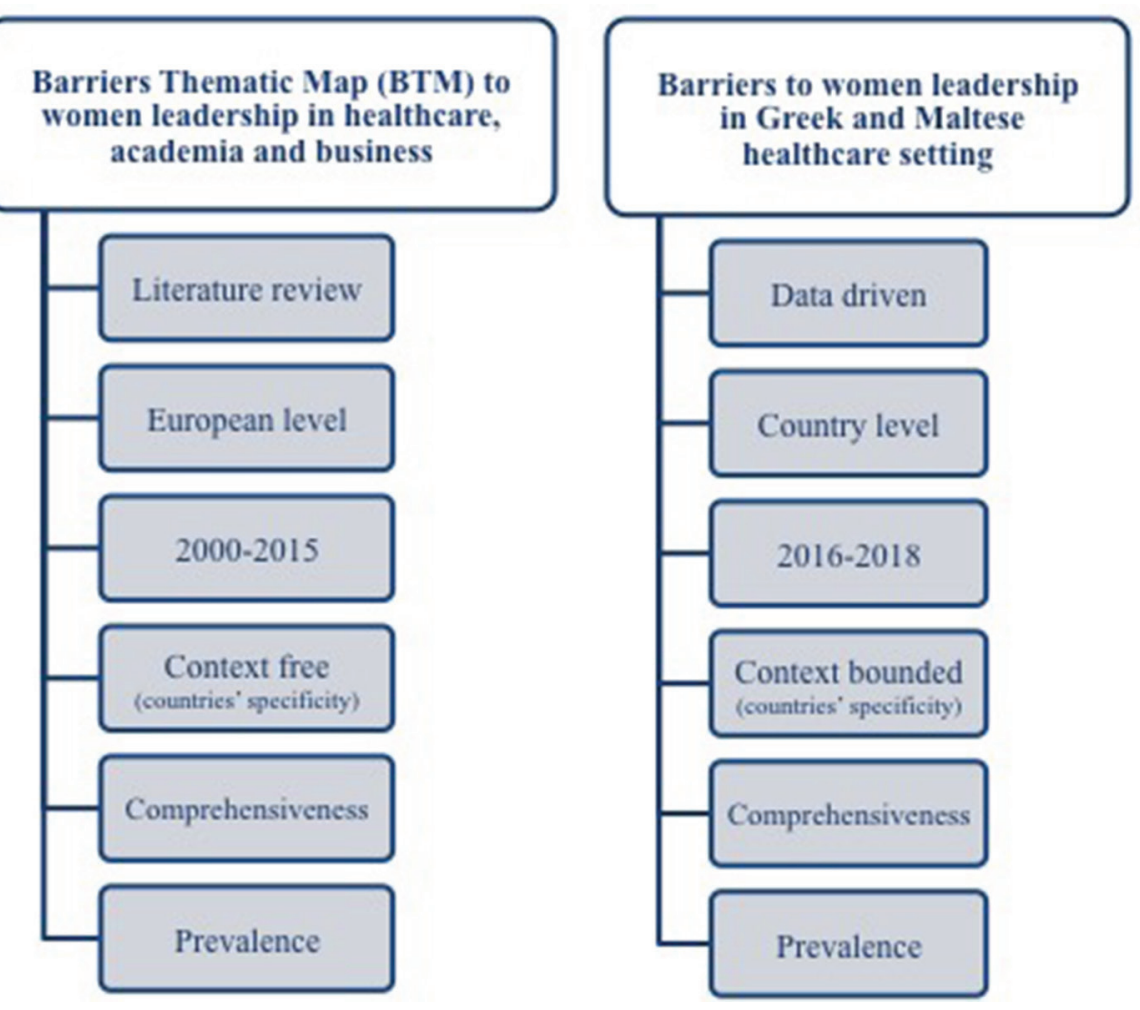

Figure 3 Characteristics of BTM study vs current study.

Abbreviation: BTM, Barriers Thematic Map.

Data were examined using directed content analysis to identify and analyze themes. ${ }^{53}$ These were further examined to explore the relationship among factors of interest and barriers hindering women leaders' advancement, as well as to gain informed insights on the country-specific interplay and process in shaping social reality. Thus, contextualiza- tion was addressed as an important component of theory on barriers constraining women leaders' representation in healthcare. ${ }^{54}$ Summative content analysis was then used to quantify the usage of themes (barriers) ${ }^{55}$ and allow deeper understanding of the contextual use of themes. The qualitative meta-summative method was lastly applied to interpret the 
content and discover underlying meanings. ${ }^{56,57}$ The analysis strategy applied, strengthened by the different backgrounds of the research team (academics, medical and non-medical, public health specialists), contributed to the study's ecological triangulation ${ }^{58}$ and supported reliability and validity. ${ }^{48}$ The COnsolidated criteria for REporting Qualitative research checklist was considered regarding study's qualitative research criteria and completed to ensure sound approach in data accuracy and analysis (Table S1).

\section{Results}

Twenty and twenty-one barriers to women's leadership were identified from the interview data within Greek and Maltese healthcare settings, respectively (Table 1; Figure 4). The barriers were classified into percentage order of the two explored countries to better serve the objectives of data interpretation and elaborate on the research question on countries' specificity in relation to women's underrepresentation in healthcare leadership.

The unfolding processes of cultural reality in relation to the social phenomenon being explored presented both commonalities and variations in the prevalence of the barriers identified in the Greek and Maltese healthcare settings. To avoid an excessive focus on culturalism, the authors applied the "bounded variability" concept ${ }^{59}$ on the grounds that differences between countries have limits and, therefore, explored contexts were delimited by discussed barriers. The social construction of the concept of barriers was deemed conceptually, contextually and functionally equivalent among male and female Greek and Maltese interviewees, providing a suitable grouping of experiences and perceptions.

Striking similarities and differences in identified barriers and their respective prevalence illustrate the complexity of the web of barriers within each country's sociocultural and economic substance and indicate each country's uniqueness in relation to the phenomenon being explored. Work/life balance (17\%), lack of family (spousal, namely, husband, wife, partner, mate, significant other) support (12\%), gender gap (10\%), gender bias ( $8 \%$ ) and lack of social support (6\%) featured in Greek interviewees' experiences and perceptions across healthcare settings. The top-ranking barriers presented in Malta included work/life balance (13\%), culture $(12 \%)$, lack of family (spousal) support (11\%), stereotypes (9\%), gender bias and lack of social support both ranked at $6 \%$. The barriers that were perceived less frequently in both countries were the lack of leadership skills, lack of mentoring and networking, lack of confidence, lack of flexible working environment, the gender pay gap, the queen bee syndrome ("the
Table I Barriers to women's leadership in Greek and Maltese healthcare setting (arithmetic presentation)

\begin{tabular}{|l|l|l|}
\hline Barriers to women's leadership & Greece (\%) & Malta (\%) \\
in healthcare & & \\
\hline Work/life balance & 17 & 13 \\
Lack of family (spousal) support & 12 & 11 \\
Culture & 4 & 12 \\
Gender gap & 10 & 5 \\
Stereotypes & 5 & 9 \\
Gender bias & 8 & 6 \\
Lack of social support & 6 & 6 \\
Lack of equal career advancement & 5 & 4 \\
opportunities & & \\
isolation & 3 & 5 \\
Lack of flexible working environment & 3 & 5 \\
Lack of executive sponsor & 4 & 4 \\
Lack of mentoring & 1 & 4 \\
Lack of networking & 3 & 3 \\
Lack of leadership skills & 3 & 2 \\
Gender pay gap & 3 & 1 \\
Sexual harassment & 3 & 0 \\
Lack of confidence & 2 & 3 \\
Lack of role models & 0 & 3 \\
Queen bee syndrome & 2 & 1 \\
Age & 2 & 0 \\
Glass ceiling & 0 & 2 \\
Race discrimination & 0 & 1 \\
Tokenism & 1 & 0 \\
Glass cliff & 0 & 0 \\
Personal health & 0 & \\
Limited succession planning & & \\
\hline
\end{tabular}

reluctance of successful females to support other women", p. 50$)^{60}$ and the lack of equal career opportunities.

\section{Work/life balance}

The difficulties in achieving work/life balance and the costs or sacrifices expected from women pursuing a top-level career in the field were explicitly described using negative overtones by Greek and Maltese healthcare leaders:

Work/life balance is very difficult, almost impossible to be achieved. [WA15]

and

Sometimes it does involve making sacrifices and letting go of the work/family balance. [WC8]

or

I prioritize my job; ... I chose not to raise a family. [WC7]

or

stepping out of career leading aspirations due to unforeseen family care tasks 


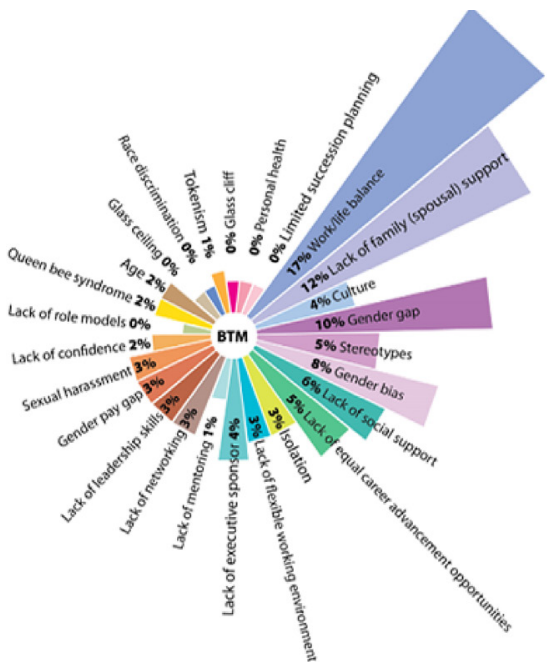

Greece: 20 barriers

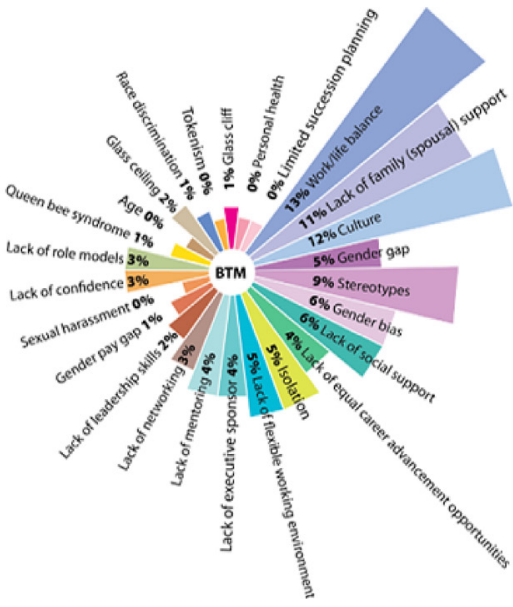

Malta: 21 barriers

( $\%=$ varying degree of barrier's prevalence)

Figure 4 Barriers to women's leadership in Greek and Maltese healthcare setting (illustrative presentation).

Abbreviation: BTM, Barriers Thematic Map.

I had to re-assess my work/life balance, my priorities, when my mother got sick. [WA1]

However, male counterparts contended:

It depends on the sacrifices a woman is willing to do. [MM24]

or at the best,

... they [women] need to get that delicate compromise.

[MM17]

assuming that getting the work/life balance challenge right is an issue firmly related to women, indicating that this is not a burden to be placed on their shoulders.

\section{Lack of family (spousal) support}

Similar gender asymmetries were noticed in addressing the lack of family (spousal) support, such as:

I told my daughter that she was good enough to become a doctor, but her life was going to suffer moving to a country where no family support was available. [MA5]

or

If you do not have spousal support, you can forget it. [WA3] and to challenges of power balance between spouses:

My ex-husband was very competitive with me on both a professional and social level; I believe my professional success cost me opportunities in my personal life. [WC19] or

They [women] are good at their science and on the other hand they have to run their household by themselves. I have seen it in my female colleagues and the young female professors. They face significant difficulties. [MA9]

\section{Culture}

Culture was considered mainly by Maltese interviewees as a structured, well-established, not easy to bend system of shared concepts, beliefs, values and roles ${ }^{59}$ granting legitimate authority to its actors and defining acceptable boundaries of power and freedom to act. Culturally, authority is not equally attributed to women:

In our Mediterranean culture, men have more of a lust for power, they are after power for the sake of power; women are more consensus seekers, cooperative and very logical, unless you make them your enemy. [MM16]

or

Mediterranean culture is more chauvinistic and has more difficulties with having women in leading positions. [MA6]

unless related to the traditional, socially constructed role of family caregiver:

Women have a more important say at home; there is still this mentality; it is a cultural influence and it is more natural for women to keep with this kind of mentality. [MC12] 
Socially legitimized expectations regarding roles, responsibilities and claims for women, except for the cases of approving husband, were also highlighted:

My husband helped me a lot; he was not envious of my career. [WM2]

or

A woman has to consider whether she wants to raise a family; for a man does not make a big difference. [MM24]

Whereas Greek leaders perceived the systemic influence of culture more flexibly:

In Greece men do not participate significantly in family issues; they participate more than previous years, but still this is not enough. [MA9]

or

It was easier for him (the General Director) to tell off a woman. [WA15]

\section{Stereotypes, gender bias, isolation, gender} gap

In both the Greek and Maltese contexts, a high prevalence ( $5 \%$ and $9 \%$, respectively) of stereotypes coupled with gender bias $(8 \%$ and $6 \%)$, isolation $(3 \%$ and $5 \%)$ and gender gap $(10 \%$ and $5 \%)$ depict a rather women-unfriendly working environment that denies equal authority on the grounds of deeply rooted power roles:

At the higher echelons of the medical profession there are few women, even though they are very good, of very high standard. The few women I know in leadership positions in medicine are high performers and must be better than their male counterparts. [MM16]

or

Women have to prove themselves constantly, which is different from men who, once they reach a certain level, are more accepted by fellow men. [WC7]

or

Here it is a male dominated situation in terms of power, $[\ldots]$ even though women are treated as equal to equal in terms of scientific competence. [WA27]

or

Our organization is male dominated; the rules of the game are quite male friendly and women unfriendly. [MM16]
Social and professional exclusion due to stereotypes and bias was articulated explicitly as being one of the major barriers to career advancement:

I avoided joining some lobbies depriving myself of some career opportunities; they were male dominated lobbies, sort of Big Boys' Club; I could not and did not want to cope with their terms. [WC19]

or

Women are in a disadvantaged position. To be honest, we have not yet reached a satisfactory level of women representation. [WM35]

\section{Lack of social support}

The strong positioning of traditional cultural values in the Maltese social reality appears to demarcate the boundaries of expected roles, responsibilities and claims for women and induces social consequences when trespassing these boundaries:

Our culture, our society, enforces a lot of guilt on women coming not only from men, but from women as well. [WA2]

or

So being a woman, a doctor and occupying a top position, is strange, you know; there is so much unjustified jealousy and criticism. [WM15]

On the contrary, Greek society seems to be more concerned about gaining power and social status; the achieved and ascribed status is desirable and sought after:

A woman in Greece coming from a middle or lower social class faces often tough criticism from her social environment should she choose to prioritize her career over her family. [MA1]

or

I may work harder than men just to receive the same recognition. [WM11]

Furthermore, a dysfunctional gap between gained professional recognition and the respective culturally legitimized authority was reported:

Medicine is a science, there is no hierarchy, but this is not always given within social system. [WM23]

Age was proposed by interviewees as a biological barrier holding back women during career stages of critical 
importance due to its coinciding with pregnancy and childbirth. In fact, both women and men reported that pregnant women or women of reproductive age are considered, even though it should not be allowed, as it is a liability to their organization's performance since

Pregnancy is not a disease and should not be addressed as such. [WM35]

Furthermore, sexual harassment as a means of power exertion to offer or to pursue career advancement (top down to bottom up and vice versa) was reported as a well-known, often unvoiced occurrence limiting opportunities on nonmeritocratic grounds.

(Un)conscious biases and stereotypes applied by gatekeepers to prevent women from entering the higher echelons were described as "male-dominated environment" and "Big Boys' Club" (WA2). These were deemed instrumental in retaining highly qualified women leaders in middle management ranks. On the other hand, complying with social expectations and in the absence of supporting structures and flexible working policies, women often opted for more family-friendly specialties. For example, specialties with programmed working hours (eg, public health, radiology, dermatology) were more likely to be sought by women compared to more time-demanding, unprogrammed and stressful specialties (eg, surgery, oncology). This has the effect of limiting career choice. Interviewees widely held that it was the women's choice to pursue a top career over raising a family. Compromising aspirations for career endeavors have also been approached as a culturally driven type of competition between spouses, affecting both genders in terms of social status. ${ }^{62}$ The paradox of the deficit in women leaders in healthcare despite their added value was acknowledged from all interviewees. "Hard workers" (MM22), "problem solvers" (MC18) and "inclusive leaders" (WC31) were the terms used to describe the competences through which women are believed to contribute significantly to organizational performance in contrast to the typical male aggressive leadership style. However, it was commonly accepted that, even though talented women have typically equal access to career advancement opportunities, career-family dilemmas, deeply socially rooted biases and organizational culture and practices reduce their odds for attaining success.

Research findings reflect interviewees' perceptions on the tripartite interactions between gender, healthcare leadership and sociocultural contexts, shedding light on the relationships between the barriers to women's leadership in the Greek and Maltese healthcare context (Table 2). All three groups of interviewees (academic, clinical and medical) presented commonalities with respect to barriers to women's leadership and the role of societal and professional culture. However, deeper exploration of the interviews may uncover critical nuances related to each group's professional context. For example, time constraints in clinical leading roles may manifest differently than in academic roles (urgency vs long hours). Similarly, it may be argued that the power interplay in professional hierarchy roles may also be considered an aggravating factor in generating barriers to women's leadership. Barriers to women's leadership related specifically to healthcare groups or to professional power interplay are of critical importance to better understand the context of gendered challenges in healthcare and merit further exploration.

\section{Discussion}

This study empirically appraised the "regimes of truth" ${ }^{\text {" with }}$ regards to gendered barriers and culturally legitimate societal power and authority in the Greek and Maltese healthcare sector. The similarities and differences explored through a country's sociocultural lens highlighted the need to address a common challenge comprehensively within a contextually bound frame. This would contribute to evidence-based research, facilitating the development of evidence-informed policy in this field.

Previously published research on barriers to women's leadership in healthcare was mainly approached at the sector or practice level. For example, Newman et al ${ }^{39,63}$ discuss several gendered constraints in pre-service and in-service education and employment systems hindering gender equality and diversity in health workforce research, leadership and governance. Similarly, Kuhlmann et al ${ }^{64,65}$ consider challenges in terms of leadership at all levels of management and organizational performance. Bismark et $\mathrm{al}^{47}$ identified and interpreted a range of barriers across medical leadership roles through the perceptions of capability, capacity and credibility. Schuh et $\mathrm{al}^{66}$ reported sociocultural constraints lowering power motivation to aspiring women leaders and, thus, mediating the link between gender and leadership role imbalances. Toh and Leonardelli ${ }^{67}$ related cultural constraints to women leaders' advancement with the degree of cultural tightness, namely, the strength of norms and social sanctions embedded in society's egalitarian practices.

Building upon the available literature on women's leadership in healthcare and on cultural pressures on women leaders, this study discusses the relationship between the pervasiveness of gendered barriers, leadership in healthcare and 
Table 2 Interview excerpts on prevailing barriers to women's leadership in Greek and Maltese healthcare setting

\begin{tabular}{|c|c|c|}
\hline Barriers & Interview excerpts from Greek healthcare leaders & Interview excerpts from Maltese healthcare leaders \\
\hline Work/life balance & $\begin{array}{l}\text { Work/life balance is very difficult, almost impossible to be } \\
\text { achieved; the majority of women bear the cost [WAI5] } \\
\text { It depends on the sacrifices a woman is willing to do; what } \\
\text { she wants to prioritize (family or career) and what to leave } \\
\text { behind [MM24] } \\
\text { I prioritize my job; being at the hospital almost } 24 / 7 \text {; I chose } \\
\text { not to raise a family [WC7] }\end{array}$ & $\begin{array}{l}\text { If you want to balance your career aspirations as a family } \\
\text { person, it's tough; especially for women; they need to get } \\
\text { that delicate compromise [MMI7] } \\
\text { Sometimes it does involve making sacrifices and letting go of } \\
\text { the work-family balance [WC8] } \\
\text { I had to re-assess my work-life balance, my priorities when } \\
\text { my mother got sick [WAI] }\end{array}$ \\
\hline $\begin{array}{l}\text { Lack of family } \\
\text { (spousal) support }\end{array}$ & $\begin{array}{l}\text { My ex-husband was very competitive with me on both } \\
\text { a professional and social level; I believe my professional } \\
\text { success cost me opportunities in my personal life [WC19] } \\
\text { They [women] are good at their science and on the other } \\
\text { hand they have to run their household by themselves. I } \\
\text { have seen it in my female colleagues and the young female } \\
\text { professors. They face significant difficulties [MA9] }\end{array}$ & $\begin{array}{l}\text { My husband helped me a lot; he was not envious of my } \\
\text { career [WM2] } \\
\text { I told my daughter that she was good enough to become a } \\
\text { doctor, but her life was going to suffer moving to a country } \\
\text { where no family support was available [MA5] } \\
\text { If you do not have spousal support, you can forget it [WA3] }\end{array}$ \\
\hline Gender gap & $\begin{array}{l}\text { Women are in a disadvantaged position. To be honest, } \\
\text { we have not yet reached a satisfactory level of women } \\
\text { representation [WM35] }\end{array}$ & $\begin{array}{l}\text { At the higher echelons of the medical profession there are } \\
\text { few women, even though they are very good, of very high } \\
\text { standard. The few women I know in leadership positions in } \\
\text { medicine are high performers and must be better than their } \\
\text { male counterparts [MMI6] }\end{array}$ \\
\hline Gender bias & $\begin{array}{l}\text { I may work harder than men just to receive the same } \\
\text { recognition [WMII] }\end{array}$ & $\begin{array}{l}\text { Women have to prove themselves constantly, which is } \\
\text { different from men who, once they reach a certain level, are } \\
\text { more accepted by fellow men [WC7] }\end{array}$ \\
\hline $\begin{array}{l}\text { Lack of social } \\
\text { support }\end{array}$ & $\begin{array}{l}\text { A woman in Greece coming from a middle or lower social } \\
\text { class faces often tough criticism from her social environment } \\
\text { should she chooses to prioritize her career over her family } \\
\text { [MAI] } \\
\text { Medicine is a science, there is no hierarchy, but this is not } \\
\text { always given within social system [WM23] }\end{array}$ & $\begin{array}{l}\text { Our culture, our society, enforces a lot of guilt on women } \\
\text { coming not only from men, but from women as well [WA2] } \\
\text { So being a woman, a doctor and occupying a top position, is } \\
\text { strange, you know; there is so much unjustified jealousy and } \\
\text { criticism [WMI5] }\end{array}$ \\
\hline Stereotypes & $\begin{array}{l}\text { Here it is a male dominated situation in terms of power ...., } \\
\text { even though women are treated as equal to equal in terms } \\
\text { of scientific competence [WA27] } \\
\text { I avoided joining some lobbies depriving myself of some } \\
\text { career opportunities; they were male dominated lobbies, } \\
\text { sort of Big Boys' Club; I could not and did not want to cope } \\
\text { with their terms [WCI9] }\end{array}$ & $\begin{array}{l}\text { Our organization is male dominated; the rules of the game } \\
\text { are quite male friendly and women unfriendly [MMI6] } \\
\text { Our faculty is still a male dominated environment, a Big } \\
\text { Boys' Club; if you look at the committees, they do not have } \\
\text { a woman member [WA2] }\end{array}$ \\
\hline Culture & $\begin{array}{l}\text { It was easier for him (the General Director) to tell off a } \\
\text { woman [WA3] } \\
\text { A woman has to consider whether she want to raise a } \\
\text { family; for a man does not make a big difference [MM24] } \\
\text { In Greece men do not participate significantly in family } \\
\text { issues; they participate more than previous years, but still } \\
\text { this is not enough [MA9] }\end{array}$ & $\begin{array}{l}\text { Women have a more important say at home; there is still } \\
\text { this mentality; it is a cultural influence and it is more natural } \\
\text { for women to keep with this kind of mentality }[\mathrm{MCI} \text { ] } \\
\text { In our Mediterranean culture, men have more of a lust for } \\
\text { power, they are after power for the sake of power; women } \\
\text { are more consensus seekers, cooperative and very logical, } \\
\text { unless you make them your enemy [MMI6] } \\
\text { Mediterranean culture is more chauvinistic and has more } \\
\text { difficulties with having women in leading positions [MA6] }\end{array}$ \\
\hline
\end{tabular}

Abbreviations: MA, man - academic setting; MC, man - clinical setting; MM, man - medical setting; MW, woman - medical setting; WA, woman - academic setting; WC, woman - clinical setting.

country's sociocultural specificities. The plethora of barriers (20 for Greece and 21 for Malta) with striking differences in the reported frequency corroborates essential sociocultural features of EU-Med countries. Taking into account that the conceptualization and operationalization of barriers were consistent across interviewees and that leadership is largely shaped by dynamic relationships between context, gender and culture, ${ }^{68}$ it may be deduced that gender asymmetries in terms of power and authority are socially and culturally defined within a country's context.

Cultural expressions include the ability to gain compliance and recognition, the distinction between power and culturally legitimate authority, ${ }^{9}$ as indicated by the

I may work harder than men just to receive the same recognition. [WM11] 
comment. Yet, generalization may be dangerous and lead to misunderstandings and prejudices ${ }^{1}$ unless subculture context, such as the healthcare profession, is taken into consideration. Paraphrasing Parsons, ${ }^{69}$ it may be argued that anything so general as gender asymmetries may be the result of a canvas of different factors deeply involved in the foundations of society, the qualities of which are sociocultural dependent. In alignment, the Maltese approach that

Men have more of a lust for power, they are after power for the sake of power; women are more consensus seekers, cooperative and very logical. [MM16]

contrasting with the Greek

It was easier for him (the General Director) to tell off a woman. [WA15]

manifests the gradation of cultural effects' strength on gender, power and authority relationship within countries' healthcare sociocultural contexts; the cultural stiffness Maltese society experiences to overcome deeply rooted perceptions is well evidenced also by the yielded prevalence on "culture" (Malta: 12\%, Greece: 4\%).

Following Durkheim, ${ }^{11}$ that the structure and quality of social relationships in terms of private life influence modes of thinking and cultural interaction, it may be suggested that gender-ascribed roles and responsibilities have been institutionalized and culturally legitimized in both countries. Work/life balance and lack of family (spousal) support scored high in Greek (17\%, 12\%) and Maltese (13\%, 11\%) settings underpinned with particular socioeconomic features; for example, Greek women were observed to opt for lower and less-rewarding but economically safer positions to secure support for their families due to the economic crisis in Greece; in contrast, the Maltese women were found to opt for part-time or lower level jobs aligning with the ascribed sociocultural obligation to prioritize family tasks over career. However, even in Sweden, widely considered to be a socially progressive country which may lend itself to work/life studies standing out in its statutory requirements in the field, culture and cultural differences are considered more important factors than legal measures toward achieving balance between personal and professional life. ${ }^{70}$ Hence, it may be argued that culture's tightness expressed in norms and legitimizations may strengthen deeply established practices, resulting in less power and authority for women, thus leading to women's leadership deficit. ${ }^{67}$ Hence, persisting underrepresentation of women leaders may be approached by addressing the tight control societal culture exerts over its subdivisions and their constituents. In line with this, Fox et $\mathrm{al}^{71}$ noted that the hierarchical gender stratification of careers is being seconded by informal gender classifications in the society. This was also reported by an interviewee

Medicine is a science, there is no hierarchy, but this is not always given within social system. [WM23]

Nonetheless, health professions are still held in high regard socially. ${ }^{72}$

However, even though culture should be considered a mix of constant influences, the boundaries among societies are vague. ${ }^{1}$ It may be claimed that in explored sector, societal culture is experienced by some as a resisting barrier to professional advancement and subsequent social change and by others as an alibi for not leaving a personal comfort zone. For example, women's leadership is perceived positively by Maltese male leaders, but still they settle with the family-related constraints imposed to women by local culture. Similarly, Greek male leaders recognize the systemic influence of culture in family-related issues and the small steps made toward change; yet, they acknowledge the long way to go to achieve an acceptable balance in family/work responsibilities. It may be argued that the analogy applies for the men's perceptions of women's leadership; all male interviewees acknowledged the leadership potential of their female counterparts, both at scientific and output levels; they also accepted that the barriers encountered by women in acquiring leading positions are many and complicated and, oftentimes, societal and professional cultures do not provide the required authorization to society members to function differently. The paradox of women's leadership challenges lies on the observation that women perceive the barriers hindering their career advancement the same way as men do. Despite potential underlying professional power struggles, which may happen in any professional interaction and among all genders, all interviewees' perceptions recognized the impact of societal culture on women's leadership. The observed cultural tightness seems to moderate the degree to which egalitarian practices may be receptive by social dividends to accept, implement and sustain such changes. However, healthcare professions being in high social regard, their potential to serve as a catalyst to social and cultural transformation, to challenge established norms and values and offer role models to social settings should not be underestimated. Considering the multiple social identities a person bears and the societal impact that they may generate, it may be argued that healthcare leaders should be reckoned as a critical component in an agenda for positive social change. 
The present study illuminated the discursive dynamics among gender, professional leadership and societal culture shaping mechanisms that influence social behavior and women's professional choices. Gendered barriers to healthcare leadership within country's sociocultural contexts may be better addressed by taking into consideration the evidence of the barriers within country's specificity that adversely impact women's leadership opportunities. Further research on the impact of these tripartite interactions across cultures is very much needed.

\section{Implications}

People grow and change within the realm of their relationships. ${ }^{73}$ Acker ${ }^{74}$ described the dynamics produced from interactions of gender, hierarchy and sociocultural setting as "inequality regimes", embodying perceptions on authority, power, leadership and more. Bringing change requires challenging traditional, culturally rooted views and values which are influenced in an untraceable, constant and timeless way. Rather than put forward a single causal proposal to empower change, authors propose a tripartite conceptual framework which links a country's sociocultural contexts with comprehensive data on gendered barriers harvested from the healthcare sector (Figure 5).

Addressing the durability and transferability of gendered barriers within sector and country contexts, a reality check may be provided via barriers' detailed mapping and prevalence through country-specific lenses, such as socioeconomic

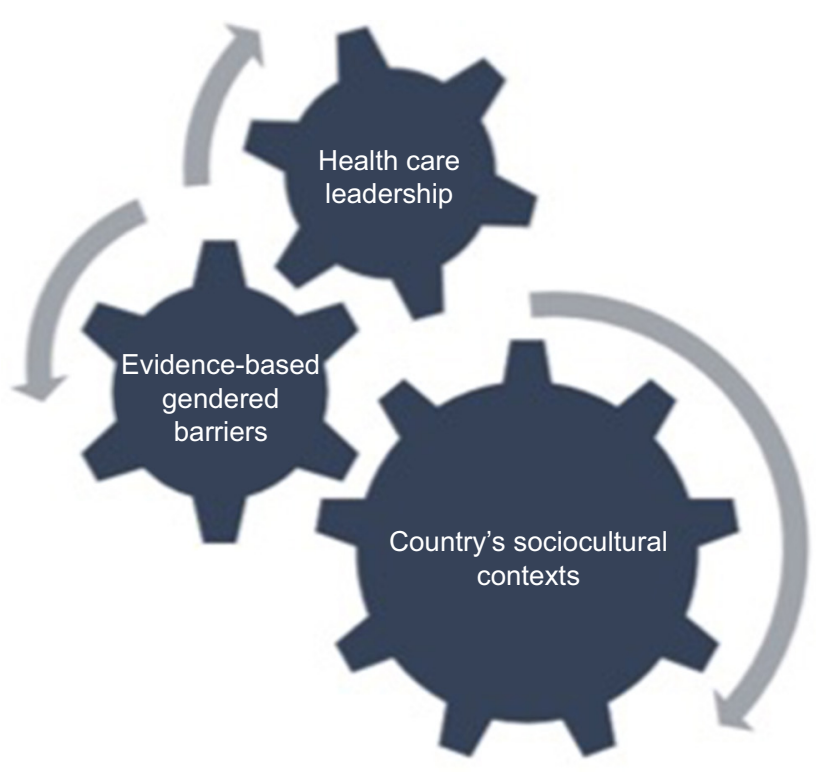

Figure 5 Conceptual framework to address gendered barriers to healthcare leadership within country's sociocultural contexts. and cultural contexts. Policies to equalize career opportunities may suffer from blind spots; for example, policy measures may address a lack of flexible working environments that give flexible work schedules to young parents, leaving though untouched sexual harassment challenges or the needs for leadership, mentoring and inclusion training programs. Thereby, mapping and evaluating the barriers and their prevalence may provide a "snapshot" to gendered challenges in organizations and support meaningful, progressive practices eschewing resources' waste in fragmentary, fashionable interventions. For example, application of an easy-to-use online toolkit providing anonymously data on barriers to women's leadership advancement in healthcare organizations may offer a reliable basis to assess existing gendered policies and practices. Nonetheless, further research is recommended to assess required gendered organizational policy changes and expected benefits for both healthcare organizations and society.

Prior research asserts culture has been the "wooden leg" of policies, ${ }^{75}$ overriding statutory efforts at change. Policymakers may be better informed by a comprehensive, evidenced-based approach responsive to country's sociocultural specificity and may develop policies and practices resonating to actual gendered needs and gaps. In that line, society and its subdivisions may experience a more effective and smooth transition toward desirable social balance and equality within work and social contexts.

\section{Limitations}

The authors acknowledge the study's limitations resulting from the constraints posed by the finite time and resources for this research. Convenience and snowballing sampling may be considered a limitation as the lack of random selection does not ensure representativeness. For example, the lack of interviewees residing in rural areas may have missed an important and different perspective. However, the interviewees' diverse origins and accumulated experiences provided a rich source of data on which to base meaningful analysis.

The directed content approach to the analysis also has some inherent limitations in terms of researchers sticking to existing theory and not recognizing potential contextual aspects of the researched phenomena that may limit the applicability of such theory. ${ }^{53}$ To address these limitations and achieve neutrality or confirmability of trustworthiness, research team members, except $\mathrm{SK}$ and $\mathrm{KC}$, examined those theme definitions before the team undertook the study.

The "coding down" approach to theme development introduces a limitation in terms of potential narrowing perceived 
notions from interview content. However, published literature offered the researchers the possibility to make inferences from new data.

Regarding language limitations on the translation of the interviews' content, translators' expertise in the subject area may not have been adequate to translate subtle nuances expressed by the interviewees.

The interviewees might have been susceptible toward study's topic since their participation has been related to their work area. The Hawthorne effect and reporting bias ${ }^{76}$ may have occurred in interviewees' responses due to their leading position. Still the study is considered to have made an empirical contribution to the literature on discursive dynamics on barriers to women's professional advancement through the country-specific cultural lens.

Nuances on potential similarities and differences on perceptions about barriers among explored healthcare groups (academic, clinical and medical) have not been discussed in detail as they are not within the scope of this study. Similarly, gendered professional hierarchies and the underlying power interplay, such as doctor-nurse and/or midwife, have not been deeply elaborated. The authors acknowledge the contribution of such findings in the field of women's leadership in healthcare; to this end, the research team proposes to further explore the professional power interplay through the lens of gender in healthcare.

The transferability of the study findings across regional and international contexts may be limited. Expansion of the study to include neighboring countries in the region would add to the trustworthiness of the findings. The study would also benefit from further exploration of additional factors such as employment contract variations in public/private sectors, subsectors' particularities and implications from migratory pressure.

\section{Conclusion}

The study explored the gendered barriers to women's leadership in healthcare through a country-specific approach. Findings unveiled underlying interactions among gender, leadership and country's sociocultural contexts, which may elucidate the varying degrees of strength of norms and barriers embedded in society's egalitarian practices. Cultural tightness can act as an alibi or barrier against sociocultural transformation. A conceptual framework is proposed to address evidence-based research in the field and inform policymakers in developing sector- and country-specific policies for advancing women's leadership in healthcare.

\section{Author contributions}

$\mathrm{SK}$ and $\mathrm{KC}$ were involved in the conception and design of the study. SK and LC conducted the interviews. SK and EP checked the translated Greek texts. KC, SB, EP and MP were involved in the extraction of themes and the pattern matching technique. All authors contributed to data analysis, drafting and revising the article, gave final approval of the version to be published, and agree to be accountable for all aspects of the work.

\section{Disclosure}

The authors report no conflicts of interest in this work.

\section{References}

1. Helman CG. Culture, Health and Illness. London: CRC Press; 2007.

2. Leach ER. Social Anthropology. New York, USA: Oxford University Press; 1982.

3. Shields SA. Gender: an intersectionality perspective. Sex Roles. 2008;59(5-6):301-311.

4. Collins PH. Black Feminist Thought: Knowledge, Consciousness, and the Politics of Empowerment. 2nd ed. New York, NY: Routledge; 2000.

5. Maurice M. Méthode comparative et analyse sociétale: les implications théoriques des comparaisons internationales [Comparative method and societal analysis. The theoretical implications of international comparisons]. Sociol Trav. 1989;31(2):175-191.

6. Foucault M. The Foucault Effect: Studies in Governmentality. Chicago, USA University of Chicago Press; 1991.

7. Hayward CR. D-facing power. Polity. 1998;31(1):1-22.

8. Eagly AH, Chin JL. Diversity and leadership in a changing world. Am Psychol. 2010;65(3):216-224.

9. Rosaldo MZ. Woman, culture, and society: a theoretical overview. In: Woman Culture, and Society. Stanford, CA, USA: Stanford University Press: $1974 ; 21$.

10. Durkheim E. Über soziale Arbeitsteilung. Studie über die Organisation höherer Gesellschaften ["Social Division of Labor, Study on the Organization of Higher Societies"] Frankfurt: Suhrkamp. 1988;2.

11. Mestrovic S. Durkheim and Postmodern Culture. New York, USA: Routledge; 2017.

12. Azzopardi-Muscat N, Buttigieg S, Calleja N, Merkur S. Malta: health system review. Health Syst Transit. 2017;19(1):1-137.

13. Economou C, Kaitelidou D, Karanikolos M, Maresso A. Greece: health system review. Health Syst Transit. 2017;19(5):1-192.

14. United Nations Interregional Crime and Justice Research Institute. The impact of the crisis on gender equality and women's wellbeing in the European Union Mediterranean countries. Available from: http://www. unicri.it/in_focus/on/vaw_report. Accessed June 3, 2018.

15. European Institute for Gender Equality (EIGE). Gender Equality Index; 2017. Available from: https://eige.europa.eu/gender-equalityindex/2015/. Accessed March 14, 2018.

16. European Commission. Labor Market and Entrepreneurship. Overcoming Gender Stereotypes. Country Report for Malta. Available from: http:/ www.afaemme.org/projects/closed/labour-market-and-entrepreneurshipovercoming-gender-stereotypes. Accessed February 2, 2018.

17. World Economic Forum. The Global Gender Gap Report; 2017. Available from: https://www.weforum.org/reports/the-global-gender-gapreport-2017. Accessed May 13, 2018.

18. Mckee M, Stuckler D. Health effects of the financial crisis: lessons from Greece. Lancet Public Health. 2016;1(2):e40-e41.

19. Moustakas C. Phenomenological Research Methods. New York, NY: Sage Publications; 1994.

20. Mossialos E, Allin S, Davaki K. Analysing the Greek health system: a tale of fragmentation and inertia. Health Econ. 2005;14(Suppl 1):S151-S168. 
21. Economou C, Kaitelidou D, Kentikelenis A, Sissouras A, Maresso A. The impact of the financial crisis on the health system and health in Greece. In: Economic Crisis, Health Systems and Health in Europe: Country Experience. Copenhagen, Denmark: WHO/European Observatory on Health Systems and Policies; 2014.

22. Vlachadis N, Kornarou E. Increase in stillbirths in Greece is linked to the economic crisis. BMJ. 2013;346:f1061.

23. Stuckler D, Basu S, Suhrcke M, Coutts A, Mckee M. The public health effect of economic crises and alternative policy responses in Europe: an empirical analysis. Lancet. 2009;374(9686):315-323.

24. European Parliament. The policy in gender equality in Greece. Available from: http://www.europarl.europa.eu/RegData/etudes/note/ join/2013/493028/IPOL-FEMM_NT(2013)493028_EN.pdf. Accessed March 3, 2018.

25. Karamessini M. Labour market impact of four recessions on women and men in Greece: comparative analysis in a long-term perspective. Soc Cohes Dev. 2010;7(2):93-104.

26. Cholezas I, Tsakloglou P. Gender earnings differentials in the Greek labour market. Economic Policy Studies. 2006. Greek.

27. Friedl E. The position of women: appearance and reality. Anthropol $Q$. 1967;40(3):97-108.

28. Georgas J. Changing family values in Greece: from collectivist to individualist. J Cross Cult Psychol. 1989;20(1):80-91.

29. Karamessini M, Ioakimoglou E. Wage determination and the gender pay gap: a feminist political economy analysis and decomposition. Fem Econ. 2007;13(1):31-66.

30. Kalikadien M. Pathways \& Policies to Tackle the Under-representation of Women in Academic Leadership in Malta. A Case Study on the Perspectives of Female Academic Leaders in Malta's Health Sector [dissertation on MSc Public Policy and Human Development]. Maastricht: Maastricht University; 2014.

31. Scicluna A. Maltese Women: Health, Care and Work 1850s-1900s [master's thesis]. Msida: University of Malta; 2013.

32. Cusens S. The Role of Women in World War II: the Case of Malta [master's thesis]. Msida: University of Malta; 2014.

33. Abela A, Frosh S, Dowling E. Uncovering beliefs embedded in the culture and its implications for practice: the case of Maltese married couples. J Fam Ther. 2005;27(1):3-23.

34. Camilleri P. The Rise and Rise of the Female Graduate: Some milestones in tertiary education for women in Malta. University of Malta Annual Report. 2006. Available from: https://www.um.edu.mt/_data/assets/ pdf_file/0003/88941/theriseandrise.pdf. Accessed October 12, 2018.

35. Hantrais L, Mangen S. editors. Cross-National Research Methodology and Practice. London: Routledge; 2013.

36. OECD. Gender equality. Available from: http://www.oecd.org/gender/ data/women-make-up-most-of-the-health-sector-workers-but-they-areunder-represented-in-high-skilled-jobs.htm. Accessed September 27, 2018.

37. Human Resources for Health. Global Resource Center. Resource spotlight: gender and health workforce statistics. Available from: http://www.hrhresourcecenter.org/gender_stats. Accessed March 10, 2017.

38. Lerch-Pieper N, Brander S, Valarino I, Zurbriggen C, Maurer E, Herr W. Challenging the "leaky pipeline" in faculties of medicine. Available from: https://smw.ch/en/op-eds/post/challenging-the-leaky-pipeline-infaculties-of-medicine/. Accessed June 30, 2018.

39. Newman C, Chama PK, Mugisha M, Matsiko CW, Oketcho V. Reasons behind current gender imbalances in senior global health roles and the practice and policy changes that can catalyze organizational change. Glob Health Epidemiol Genom. 2017;2:e19.

40. Czabanowska K, Domagała A, Kalaitzi S, et al. Exploring the added value of women health care managers in Poland. Mater Sociomed. 2017;29(4):280-285.

41. Downs JA, Mathad JS, Reif LK, et al. The ripple effect: why promoting female leadership in global health matters. Public Health Action. 2016;6(4):210-211.
42. World Health Organization. Gender, Equity and Human Rights. Geneva: World Health Organization. Available from: http://www.who. int/gender-equity-rights/understanding/gender-definition/en/. Accessed on November 2, 2018.

43. Lammers CJ, Hickson DJ. Are organizations culture-bound? In: Organizations Alike and Unlike. London: Routledge and Kegan Paul; 1979:402-403.

44. Guba EG, Lincoln YS. Competing paradigms in qualitative research. In: Handbook of Qualitative Research. Thousand Oaks, CA, US: Sage Publications, Inc.; 1994;2(163-194): 105.

45. Seidman I. Interviewing as Qualitative Research: a Guide for Researchers in Education and the Social Sciences. New York, USA: Teachers College Press; 2013.

46. Ravitch SM, Carl NM. Qualitative Research: Bridging the Conceptual, Theoretical, and Methodological. Thousand Oaks, CA, US: Sage Publications, Inc.; 2015.

47. Bismark M, Morris J, Thomas L, Loh E, Phelps G, Dickinson H. Reasons and remedies for under-representation of women in medical leadership roles: a qualitative study from Australia. BMJ Open. 2015;5(11):e009384.

48. Lincoln YS, Guba EG. Naturalistic Inquiry. Thousand Oaks, CA, US: Sage Publications, Inc.; 1985;75.

49. Kalaitzi S, Czabanowska K, Fowler-Davis S, Brand H. Women leadership barriers in healthcare, academia and business. Equality, Diversity and Inclusion: An International Journal. 2017;36(5):457-474.

50. World Health Organization. Strengthening Women's Leadership in Public Health in Ukraine. Geneva: World Health Organization. Available from: http://www.euro.who.int/en/countries/ukraine/news/ news/2017/05/strengthening-womens-leadership-in-public-health-inukraine. Accessed March 15, 2018.

51. Kalaitzi S, Czabanowska K. Women's leadership in healthcare the three faceted quest. Eur J Public Health. 2016;26(Suppl 1): ckw166-018.

52. Patton MQ. Qualitative Evaluation and Research Methods. Thousand Oaks, CA, US: Sage Publications, Inc.; 1990.

53. Hsieh HF, Shannon SE. Three approaches to qualitative content analysis. Qual Health Res. 2005;15(9):1277-1288.

54. Mayring P. Qualitative content analysis: theoretical background and procedures. In: Approaches to Qualitative Research in Mathematics Education. Dordrecht: Springer; 2015:365-380.

55. Potter WJ, Levine-Donnerstein D. Rethinking validity and reliability in content analysis. J Appl Commun Res. 1999.

56. Morgan DL. Qualitative content analysis: a guide to paths not taken. Qual Health Res. 1993;3(1):112-121.

57. Sandelowski M, Barroso J, Voils CI. Using qualitative metasummary to synthesize qualitative and quantitative descriptive findings. Res Nurs Health. 2007;30(1):99-111.

58. Barnett-Page E, Thomas J. Methods for the synthesis of qualitative research: a critical review. BMC Med Res Methodol. 2009;9(1):59.

59. Rose R, Mackenzie WJM. Comparing forms of comparative analysis. Polit Stud (Oxf). 1991;39(3):446-462.

60. Ellemers N. Women at work how organizational features impact career development. Policy Insights Behav Brain Sci. 2014;1(1):46-54.

61. Keesing RM, Strathern A. Fieldwork. Cultural Anthropology: a Contemporary Perspective. Fort Worth: Harcourt Brace College Publishers; 1998.

62. Ely RJ, Ibarra H, Kolb DM. Taking gender into account: theory and design for women's leadership development programs. Acad Manag Learn Educ. 2011;10(3):474-493.

63. Newman C, Pacqué-Margolis S, Frymus D. Integration of gendertransformative interventions into health professional education reform for the 21st century: implications of an expert review. Hum Resour Health. 2016:14:14.

64. Kuhlmann E, Batenburg R, Dussault G. Health workforce governance in Europe: where are we going? Health Policy. 2015;119(12): $1515-1516$. 
65. Kuhlmann E, Ovseiko PV, Kurmeyer C, et al. Closing the gender leadership gap: a multi-centre cross-country comparison of women in management and leadership in academic health centres in the European Union. Hum Resour Health. 2017;15(1):2.

66. Schuh SC, Hernandez Bark AS, van Quaquebeke N, et al. Gender differences in leadership role occupancy: the mediating role of power motivation. J Bus Ethics. 2014;120(3):363-379.

67. Toh SM, Leonardelli GJ. Cultural constraints on the emergence of women as leaders. J World Bus. 2012;47(4):604-611.

68. Klenke K. Women and Leadership: A Contextual Perspective. New York, NY, USA: Springer Publishing Company; 2004.

69. Parsons T. Evolutionary universals in society. Am Soc Rev. 1964;29(3):339-357.

70. Lane C. Work - life in Sweden. Executive briefing series. Center for Work \& Family. Boston College. Available from: https:/www.bc.edu/ content/dam/files/centers/cwf/research/publications3/executivebriefingseries-2/ExecutiveBriefing_Work-LifeinSweden.pdf. Accessed: September 17, 2018
71. Fox MF, Whittington K, Linkova M. Gender, (in) equity, and the scientific workforce. In: Handbook of Science and Technology Studies. Cambridge: Mass MIT Press; 2017.

72. Riska E. Medical Careers and Feminist Agendas. American, Scandinavian and Russian Women Physicians, New York: Adline De Gruyter; 2001.

73. Holloway I. Qualitative Research in Health Care. Berkshire, England: McGraw-Hill Education; 2005.

74. Acker J. Inequality regimes: gender, class, and race in organizations. Gend Soc. 2006;20(4):441-464.

75. Allard K, Haas L, Hwang CP. Family-supportive organizational culture and fathers' experiences of work-family conflict in Sweden. Gend Work Organ. 2011;18(2):141-157.

76. Bowling A. Research Methods in Health: Investigating Health and Health Services. Berkshire, England: McGraw-Hill Education; 2014. 


\section{Supplementary material}

Table SI COREQ checklist for Kalaitzi et al (2019) "Women, healthcare leadership and societal culture - a qualitative study"

\begin{tabular}{|c|c|c|c|}
\hline Topic & Item no. & Guide questions/description & Reported on page no. \\
\hline \multicolumn{4}{|c|}{ Domain I: Research team and reflexivity } \\
\hline \multicolumn{4}{|l|}{ Personal characteristics } \\
\hline Interviewer/facilitator & 1 & Which author/s conducted the interview or focus group? & SK/LC (p. II) \\
\hline Credentials & 2 & $\begin{array}{l}\text { What were the researcher's credentials? For example, PhD, } \\
\text { MD }\end{array}$ & $\mathrm{PhDc} / \mathrm{PhD}$ \\
\hline Occupation & 3 & What was their occupation at the time of the study? & Doctoral student/researcher \\
\hline Gender & 4 & Was the researcher male or female? & Female(s) \\
\hline Experience and training & 5 & What experience or training did the researcher have? & Official/field training \\
\hline \multicolumn{4}{|l|}{ Relationship with participants } \\
\hline Relationship established & 6 & Was a relationship established prior to study commencement? & No \\
\hline $\begin{array}{l}\text { Participant knowledge of the } \\
\text { interviewer }\end{array}$ & 7 & $\begin{array}{l}\text { What did the participants know about the researcher? For } \\
\text { example, personal goals, reasons for doing the research }\end{array}$ & $\begin{array}{l}\text { Participants were informed } \\
\text { about the reasons of this } \\
\text { research (p. II) }\end{array}$ \\
\hline Interviewer characteristics & 8 & $\begin{array}{l}\text { What characteristics were reported about the interviewer/ } \\
\text { facilitator? For example, bias, assumptions, reasons and } \\
\text { interests in the research topic }\end{array}$ & $\begin{array}{l}\text { Interests (research, paper } \\
\text { publication) (p. II) }\end{array}$ \\
\hline \multicolumn{4}{|l|}{ Domain 2: Study design } \\
\hline \multicolumn{4}{|l|}{ Theoretical framework } \\
\hline $\begin{array}{l}\text { Methodological orientation } \\
\text { and theory }\end{array}$ & 9 & $\begin{array}{l}\text { What methodological orientation was stated to underpin } \\
\text { the study? For example, grounded theory, discourse analysis, } \\
\text { ethnography, phenomenology, content analysis }\end{array}$ & Directed content analysis (p. 13) \\
\hline \multicolumn{4}{|l|}{ Participant selection } \\
\hline Sampling & 10 & $\begin{array}{l}\text { How were participants selected? For example, purposive, } \\
\text { convenience, consecutive, snowball }\end{array}$ & Purposeful and snowball (p. 10) \\
\hline Method of approach & 11 & $\begin{array}{l}\text { How were participants approached? For example, face-to- } \\
\text { face, telephone, mail, email }\end{array}$ & Email, telephone (p. I0) \\
\hline Sample size & 12 & How many participants were in the study? & 36 (p. 10) \\
\hline Non-participation & 13 & $\begin{array}{l}\text { How many people refused to participate or dropped out? } \\
\text { Reasons? }\end{array}$ & Two due to time constraints \\
\hline \multicolumn{4}{|l|}{ Setting } \\
\hline Setting of data collection & 14 & $\begin{array}{l}\text { Where was the data collected? For example, home, clinic, } \\
\text { workplace }\end{array}$ & Workplace (p. II) \\
\hline Presence of non-participants & 15 & $\begin{array}{l}\text { Was anyone else present besides the participants and } \\
\text { researchers? }\end{array}$ & No (p. II) \\
\hline Description of sample & 16 & $\begin{array}{l}\text { What are the important characteristics of the sample? For } \\
\text { example, demographic data, date }\end{array}$ & $\begin{array}{l}\text { Highly educated, healthcare } \\
\text { professionals (p. 10) }\end{array}$ \\
\hline \multicolumn{4}{|l|}{ Data collection } \\
\hline Interview guide & 17 & $\begin{array}{l}\text { Were questions, prompts, guides provided by the authors? } \\
\text { Was it pilot tested? }\end{array}$ & $\begin{array}{l}\text { Questions, prompts; tested with } \\
\text { focus groups (p. II, I3) }\end{array}$ \\
\hline Repeat interviews & 18 & Were repeat interviews carried out? If yes, how many? & No \\
\hline Audio/visual recording & 19 & $\begin{array}{l}\text { Did the research use audio or visual recording to collect the } \\
\text { data? }\end{array}$ & Audio (p. II) \\
\hline Field notes & 20 & $\begin{array}{l}\text { Were field notes made during and/or after the interview or } \\
\text { focus group? }\end{array}$ & Yes (p. II) \\
\hline Duration & 21 & What was the duration of the interviews or focus group? & $20-50$ minutes $(\mathrm{p} . \mathrm{II})$ \\
\hline Data saturation & 22 & Was data saturation discussed? & Yes (p. 10, I3) \\
\hline Transcripts returned & 23 & $\begin{array}{l}\text { Were transcripts returned to participants for comment and/ } \\
\text { or correction? }\end{array}$ & $\begin{array}{l}\text { Yes, but declined due to time } \\
\text { constraints (p. II) }\end{array}$ \\
\hline \multicolumn{4}{|c|}{ Domain 3: analysis and findings } \\
\hline \multicolumn{4}{|c|}{ Data analysis } \\
\hline Number of data coders & 24 & How many data coders coded the data? & 4 (p. I3) \\
\hline Description of the coding tree & 25 & $\begin{array}{l}\text { Did authors provide a description of the coding tree? } \\
\text { Yes (p. 12) }\end{array}$ & \\
\hline
\end{tabular}


Table SI (Continued)

\begin{tabular}{|l|l|l|l|}
\hline Topic & Item no. & Guide questions/description & Reported on page no. \\
\hline Derivation of themes & 26 & Were themes identified in advance or derived from the data? & In advance (p. I2) \\
\hline Software & 27 & What software, if applicable, was used to manage the data? & N/A \\
\hline Participant checking & 28 & Did participants provide feedback on the findings? & No \\
\hline Reporting & 29 & $\begin{array}{l}\text { Were participant quotations presented to illustrate the } \\
\text { themes/findings? } \\
\text { Was each quotation identified? For example, participant } \\
\text { number }\end{array}$ & Yes (Pp. 16-22, 25-27) \\
\hline Quotations presented & 30 & $\begin{array}{l}\text { Was there consistency between the data presented and the } \\
\text { findings? }\end{array}$ & Yes (Pp. 14-15) \\
\hline Data and findings consistent & 3 Were major themes clearly presented in the findings? & Yes (Pp. I5-2I) \\
\hline Clarity of major themes & 3 I & $\begin{array}{l}\text { Is there a description of diverse cases or discussion of minor } \\
\text { themes? }\end{array}$ & Yes (Pp. 2I-22) \\
\hline Clarity of minor themes & 32 &
\end{tabular}

Note: aDeveloped from: by permission of Oxford University Press.'

Abbreviation: COREQ, COnsolidated criteria for REporting Qualitative research.

\section{Reference}

1. Tong A, Sainsbury P, Craig J. Consolidated criteria for reporting qualitative research (COREQ): a 32-item checklist for interviews and focus groups. Int J Qual Health Care. 2007;19(6):349-357.

The Journal of Healthcare Leadership is an international, peer-reviewed, open access journal focusing on leadership for the health profession. The journal is committed to the rapid publication of research focusing on but not limited to: Healthcare policy and law; Theoretical and practical aspects of healthcare delivery; Interactions between healthcare and society and evidence-based practices;
Interdisciplinary decision-making; Philosophical and ethical issues; Hazard management; Research and opinion for health leadership; Leadership assessment. The manuscript management system is completely online and includes a very quick and fair peer-review system. Visit http://www.dovepress.com/ testimonials.php to read real quotes from published authors. 